Article

\title{
Drought Stress Affects the Response of Italian Local Tomato (Solanum lycopersicum L.) Varieties in a Genotype-Dependent Manner
}

\author{
Veronica Conti ${ }^{1, *,+}\left(\mathbb{D}\right.$, Lavinia Mareri ${ }^{1, *,+}{ }^{1}$, Claudia Faleri $^{1}$, Massimo Nepi ${ }^{1}$, Marco Romi ${ }^{1}$, \\ Giampiero Cai ${ }^{1}$ (D) and Claudio Cantini ${ }^{2}$ (D) \\ 1 Department of Life Sciences, University of Siena, Siena, SI 53100, Italy \\ 2 CNR-IBE (Consiglio Nazionale delle Ricerche-Istituto per la Bioeconomia), Follonica, GR 58022, Italy \\ * Correspondence: conti30@student.unisi.it (V.C.); lavinia.mareri@unisi.it (L.M.); \\ Tel.: +39-0577-232856 (V.C. \& L.M.) \\ + These authors contributed equally to this work.
}

Received: 2 August 2019; Accepted: 5 September 2019; Published: 7 September 2019

\begin{abstract}
Drought stress is one of the most severe conditions for plants, especially in the face of the emerging problem of global warming. This issue is important when considering economically relevant crops, including the tomato. For these plants, a promising solution is the valorization of local agrobiodiversity as a source of genetic variability. In this paper we investigated how six Italian tomato varieties react to a prolonged period of water depletion. We used a multidisciplinary approach, from genetics to plant physiology and cytology, to provide a detailed overview of the response of plants to stress. The varieties analyzed, each characterized by a specific genetic profile, showed a genotype-specific response with the variety 'Fragola' being the most resistant and the variety 'Pisanello' the most susceptible. For all the parameters evaluated, 'Fragola' performed in a manner comparable to that of control plants. On the contrary, 'Pisanello' appeared to be more affected and showed an increase in the number of stomata and a drastic increase in antioxidants, a symptom of acute oxidative stress. Our work suggests the existence of a valuable reservoir of genetic biodiversity with more drought-tolerant tomato genotypes opening the way to further exploitation and use of local germplasm in breeding programs.
\end{abstract}

Keywords: tomato; Italian varieties; drought stress; oxidative stress; physiological response

\section{Introduction}

The most common environmental factor affecting plant growth and productivity/yield is the lack or scarcity of water, a stressful condition known as "drought stress" [1]. By altering the water balance of cells and tissues, drought stress negatively affects many physiological and cellular processes, by acting both at the molecular level (e.g., by inducing protein denaturation), at the cellular level (cell collapse), and at the level of the entire plant (wilting). Drought stress is a critical current problem and its study is progressively taking on a major role; given the increased frequency of acute drought conditions due to global warming, its severity will most likely be exacerbated by future climate change [2].

Plants have developed physiological, morphological, cytologic, and biochemical responses to avoid and/or limit the consequences of drought stress [3]. From a physiological point of view, the first response of plants to severe water deficit is stomata closure aimed to prevent the transpiration water loss [4]. In addition to stomata closure, plants can also reduce stomata size in response to prolonged water lack and can alter their number, length, and width [5]. In this regard, studies have shown an increase in stomatal density under conditions of moderate drought stress, and a 
decrease in stomatal density following prolonged periods of stress [6]. However, changes in stomata number and morphology under water stress condition are dependent on the species. Despite these species-dependent responses, in all plants stomatal closure is regulated by the ABA (abscisic acid) hormone with both a hydropassive and a hydroactive way [5]. One of the main consequences of stomata closure is the decrease in the inflow of $\mathrm{CO}_{2}$ and the concomitant increase of $\mathrm{O}_{2}$ concentration into the leaves and the consequent accumulation of photosynthesis-derived electrons, which can potentially react with molecular oxygen leading to the formation of ROS (Reactive Oxygen Species). Free ROS, if abundant and accumulating for a prolonged period, can react with biological structures, damage DNA, promote protein oxidation and cause lipid peroxidation [7]. Plants respond to oxidative stress by synthesizing specific enzymes able to scavenge ROS [8] and/or to produce antioxidant molecules such as polyphenols [9]. A further mechanism of tolerance to water stress is represented by compatible solutes, which allow a fine osmotic regulation thereby maintaining turgor pressure even in stressful conditions. Osmolytes such as ammonium-based compounds (polyamines, glycine betaine, and others), or derived from sugars (trehalose, mannitol, sorbitol, and others) or amino acids (proline) are reported to perform important functions in osmotic regulation against drought stress [10].

Tomato (Solanum lycopersicum L.) is a major crop grown all over the world as it is an important dietary source of vitamins (A and C), and carotenoids such as lycopene [11]. However, despite its large-scale cultivation, it is susceptible to abiotic and biotic stresses [12,13]. Both vegetative and reproductive processes of modern tomato cultivars can be severely compromised by drought stress, which inhibits seed development, reduces vegetative growth and compromises reproduction [14,15]. During vegetative growth, drought-treated tomato plants show a reduction in biomass production associated with a decrease of leaf production and a smaller plant height compared to control plants. Not only a reduced number of leaves but also a reduction in leaf area can decrease the photosynthesis yield [16]. In this regard, Pervez et al., [16] showed that tomato seedlings are sensitive to drought with a strong inhibition of light harvesting efficiency, photochemical conversion, and photosynthetic electron transport. Concerning the effect of water deficit on tomato reproduction, it is well known that drought stress during seed development decreases seed yield by shortening the final seed filling periods. In addition to this, as proved by the vigor test, drought stress occurring during seed formation or filling resulted in reduced seedling vigor and germination [16]. Other studies reported that drought stress significantly affected tomato yield, however increasing the irrigation state under a specific level did not positively influence the tomato yield which remains stable [17-19]. In addition to yield, lack of water also influences the volume, diameter, and composition of fruits (i.e., lycopene and total soluble sugars) [20]. All these parameters are useful indicators of drought resistance/susceptibility.

The observed susceptibility to drought stress needs the development of more resistant varieties able to cope with water stress while maintaining yield [21]. In this view, genetic biodiversity can be considered as a valuable resource for the enhancement of crop yield, for the resistance to diseases and pests, and for quality improvement. It is well accepted that a wider varietal and species diversity would enable agricultural systems to support productivity over a wide range of conditions, including stressful conditions. As a signatory country of the Convention on Biological Diversity (CBD) (Rio de Janeiro, 1992), Italy has promoted a national strategy for the conservation of biodiversity. In this regard, the Tuscany region has enacted a specific law (LR 64/04) to promote the protection of biodiversity and to recover local varieties at risk of extinction by classifying and including them in a regional repertoire (Regional Bank of Germplasm). The assessment of diversity in plants is routinely performed using several techniques. In the postgenomic era, molecular markers have emerged as powerful tools for the analysis of genetic variation. Simple sequence repeats (SSRs), also known as microsatellites, are repeats of up to 100 times of simple sequences of 1-8 base pairs [22]. They are highly polymorphic, abundant, present in both coding and non-coding regions, and co-dominantly inherited giving them a high power of discrimination [23]. SSRs have been widely employed to exploit genetic diversity in different plant species [24-26] including tomato [27-29]. 
The present work aimed to study the effects of drought stress in six local varieties of Tuscan tomato (Solanum lycopersicum L.). Such varieties, registered in the Regional Bank of Germplasm, are characterized by different morphological and agronomic characteristics. Tomato plants were genetically characterized using a set of selected SSR markers previously adopted for successful variety identification [27-29]. In addition to this, the varieties were physiologically evaluated using different parameters ranging from photosynthetic activity to stem diameter and plant height. To have a more complete analysis, we investigated other parameters such as stomata density, leaf morphology, and antioxidant activity. The work provides information on how locally adapted tomato varieties cope with water scarcity and it paves the way to further studies aimed to improve the tomato crop by using plant genetic diversity.

\section{Results and Discussion}

Genetic characterization of the six local varieties was performed using a set of 16 SSR markers selected from the literature [27-29]. Ten out of the 16 selected SSRs were polymorphic. Monomorphic markers, namely LEat016, LEcag003, LEatt001, LEcag001, LEcag001, and SSR603, were thus excluded from the analysis. The allelic profile of each variety was used to obtain a phylogenetic tree through the unweighted pair-group method for arithmetic averages (UPGMA) hierarchical clustering (Figure 1). The dendrogram shows that the method used was able to discriminate the tested varieties. In fact, the phylogenetic tree grouped the six varieties and the commercial variety into two major clusters, one consisting of 'Costoluto Fiorentino', 'Pisanello', 'Quarantino' and 'Supersteak' and the other one consisting of 'Fragola', 'Canestrino di Lucca' and 'Rosso di Pitigliano'. In the first cluster, the commercial 'Supersteak' is genetically more distant to the other genotypes; similarly, 'Rosso di Pitigliano' is more distant to the other genotypes included in the second cluster. In the latter 'Costoluto Fiorentino' and 'Pisanello' are the most similar varieties. As reported by the Regional Bank of the Germplasm, the distribution of the above mentioned varieties is widely diffused in Tuscany and the cultivation of some varieties (e.g., 'Canestrino di Lucca'), originally restricted to a specific area, has been expanded to the whole region. Therefore, it is not easy to explain the differences observed in the dendrogram considering the different origins of each variety. 'Rosso di Pitigliano' is the only one whose origin (South Tuscany) matches its distribution and its genetic profile supports this evidence.

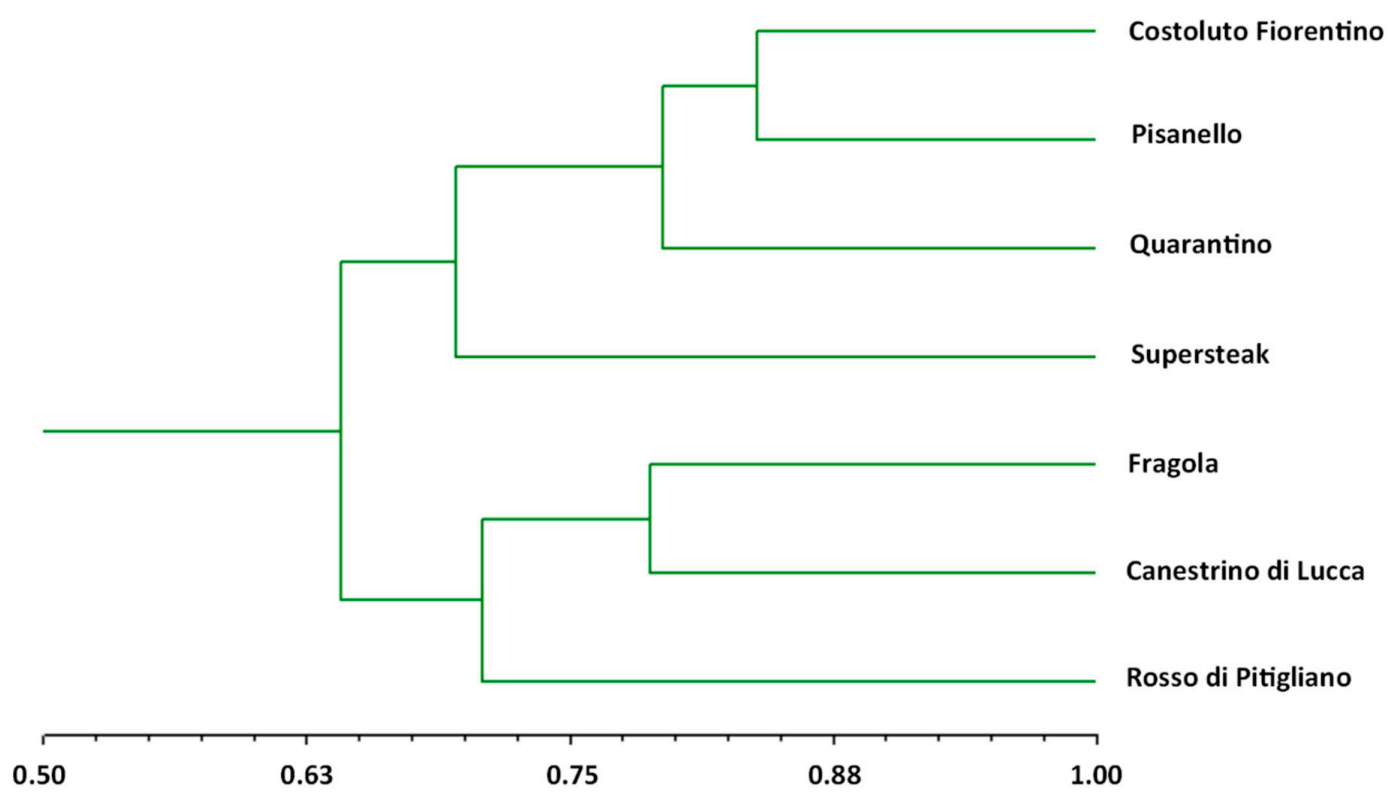

Figure 1. Hierarchical clustering (UPGMA algorithm) of six local varieties and one commercial cultivar ('Supersteak'). 
In order to evaluate how drought stress can compromise the physiology of tomato plants, we monitored a series of physiological parameters related to plant growth such as growth index, stem diameter and leaf area, as well as other parameters directly or indirectly related to photosynthesis, such as photosynthesis efficiency, performance index, and stomata number; finally, we measured other parameters related to oxidative stress (which is a consequence of drought) such as superoxide distribution and content of antioxidant molecules. The physiological measurements were used to select the most resistant and the most susceptible variety for which we performed all the above-mentioned analyses. Supplementary Figures S1-S4 show the phenotype of plants at $t_{0}$ (before treatment), $t_{1}$ (half duration of stress), and $t_{2}$ (end of stress). As can be seen, at $t_{1}$ no appreciable differences were visible while at $t_{2}$ it was clear there was a different degree of drought resistance among genotypes. Particularly, 'Fragola' seemed to be not affected and its phenotype was comparable to control (well irrigated plants). A lower level of resistance was exhibited by 'Canestrino di Lucca' and the commercial cultivar 'Supersteak' which were only partially damaged: leaves were green but lightly wilted with the edge of the lamina curved downward. More compromised appeared to be 'Costoluto Fiorentino' and 'Rosso di Pitigliano' with severely wilted and partially shriveled leaves. Such phenotype was exasperated in 'Pisanello' in which leaves were totally shriveled. In the middle scale there was 'Quarantino' whose phenotype was mildly affected, showing partially wilted leaves.

Photosynthetic efficiency is one of the processes most affected by drought stress. Particularly, as reported for other abiotic stresses, lack of water causes a serious impairment of the photosynthetic machinery with photosystem II (PSII) being one of the most susceptible components [30]. Photosynthetic efficiency can be evaluated by $\mathrm{F}_{\mathrm{v}} / \mathrm{F}_{\mathrm{m}}$ measurement that is the maximum quantum yield of PSII. The results here obtained showed that $\mathrm{F}_{\mathrm{v}} / \mathrm{F}_{\mathrm{m}}$ did not change during the first eight days of stress (Figure 2) with no differences between control and stressed plants. Changes became clear in the later stages of stress. Particularly, 'Costoluto Fiorentino', 'Rosso di Pitigliano', 'Canestrino di Lucca' showed a significant decrease in photosynthetic efficiency starting from day 12-13, with a clear decline to day 16. Among the local varieties, 'Pisanello' started a slight decline in $F_{v} / F_{m}$ value from day 10 and it remained constant until day 16 . Interestingly, the values of $F_{v} / F_{m}$ of the commercial cultivar 'Supersteak' decreased after day 8 , in contrast to local varieties. The only two exceptions were 'Quarantino' and 'Fragola' for which $\mathrm{F}_{\mathrm{v}} / \mathrm{F}_{\mathrm{m}}$ measurements remained similar in both well-watered and stressed plants for the whole period of stress. Such results show that they did not suffer serious damages even at day 16 . Similar to our results, Paknejad et al., (2007) [31] showed that in wheat, different irrigation treatments negatively influenced $\mathrm{F}_{\mathrm{v}} / \mathrm{F}_{\mathrm{m}}$ and they also described a correlation between grain yield and fluorescence paramenters (i.e., $\mathrm{F}_{\mathrm{v}} / \mathrm{F}_{\mathrm{m}}$ ): such parameters can be thus considered as reliable characteristics to adopt for evaluation of genotypic differences in drought stress tolerance.

The results of the Performance Index (PI) (Figure 3) were more variable during stress treatment, but they confirm the $\mathrm{F}_{\mathrm{v}} / \mathrm{F}_{\mathrm{m}}$ values. In fact, 'Costoluto Fiorentino', 'Rosso di Pitigliano' 'Canestrino di Lucca', 'Pisanello,' and the commercial 'Supersteak' showed a slight decrease in PI already from day 12-13 with a sharp drop at day 16. On the contrary, for 'Quarantino' and 'Fragola' the trend was similar between well-watered and treated plants. These results show that among the tested varieties the process of photosynthesis is not equally affected by drought stress. 

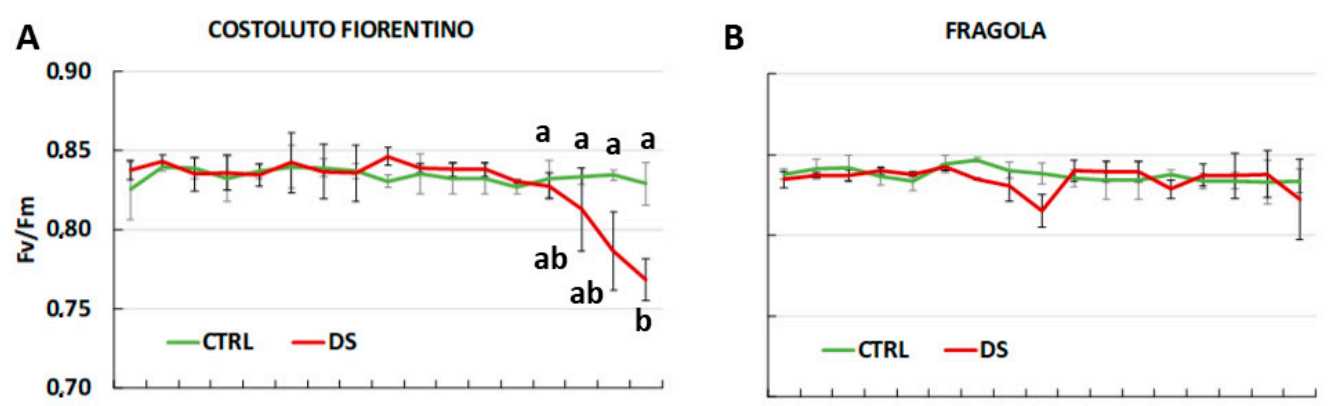

C

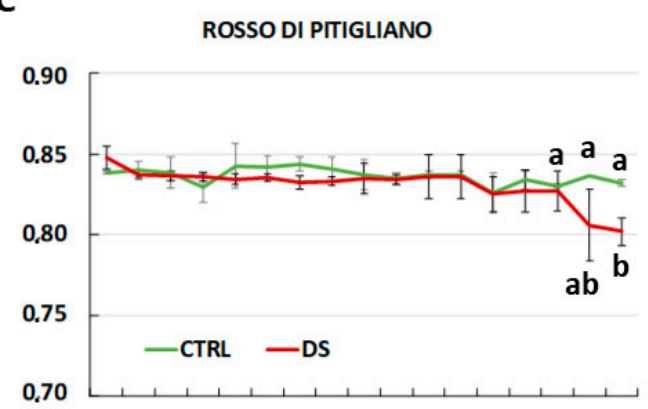

E

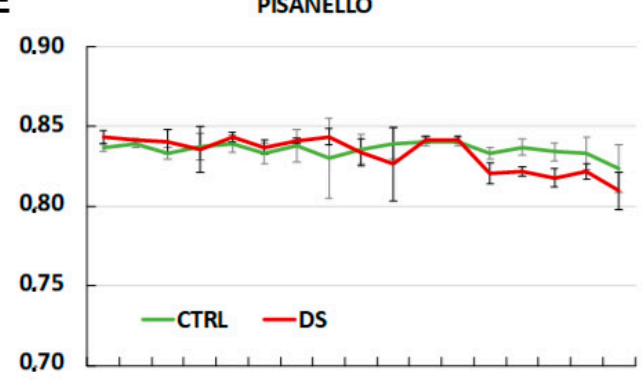

G

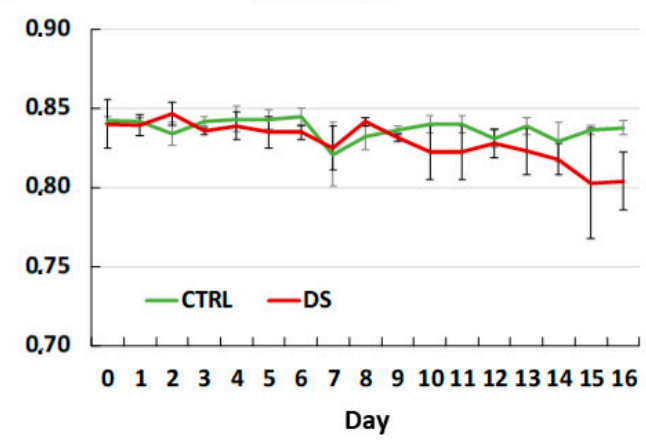

D

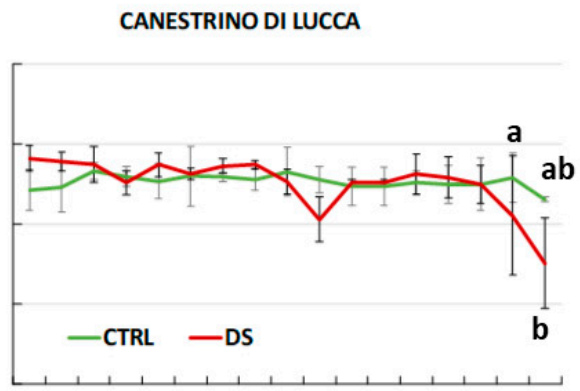

$\mathbf{F}$

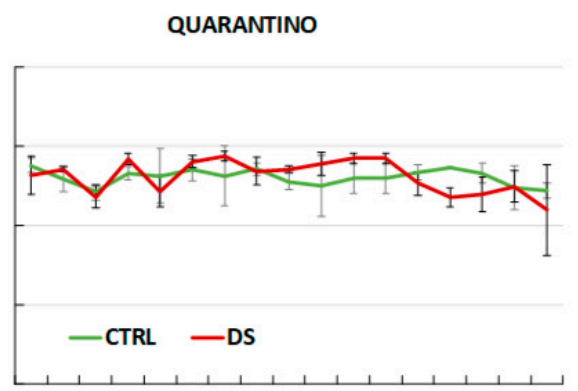

Figure 2. The maximum quantum yield of photosystem II $\left(\mathrm{F}_{\mathrm{v}} / \mathrm{F}_{\mathrm{m}}\right)$ in six local varieties $(\mathbf{A}-\mathbf{F})$ and one commercial cultivar 'Supersteak' (G) of tomato (Solanum lycopersicum L.) subjected to drought stress (no water for 16 days) relative to the controls (regularly well-watered plants). Two-way factorial ANOVA followed by Tukey post-hoc test was used to determine the statistical significance of differences. Points with the same lower-case letters do not differ significantly $(p>0.05)$.

Another physiological parameter symptomatic of stress-induced damaged is plant growth. This latter, herein expressed as growth index (GI), is linked to carbohydrate resources and energy generated by photosynthesis: stress exposure leads to over-excitation of the photosynthetic electron transport chain, alters photosystem activity determining a reduction in carbohydrate synthesis and energy needed for plant growth [32]. With a trend similar to the one reported for $F_{v} / F_{m}$, the results of $\mathrm{GI}_{1,0}$ in all the studied varieties did not show significant differences between control and stressed 
plants with the only exception being the commercial 'Supersteak' for which the $\mathrm{GI}_{1,0}$ value significantly increased. In contrast to that observed for $\mathrm{GI}_{1,0}, \mathrm{GI}_{2,0}$ was severely compromised for all stressed plants. For all varieties, including the commercial genotype, a sharp drop was recorded, with 'Rosso di Pitigliano' and 'Pisanello' being the most damaged varieties (Figure 4). Our results are in agreement with other studies that reported a reduction in plant growth under water deficit. In this regard, Wahb-Allah et al., 2007 showed that tomato plant height was inhibited by decreasing the amount of irrigation water. Interestingly and similar to our results, authors also described a genotype-dependent effect with some genotypes less affected than others [17].

A

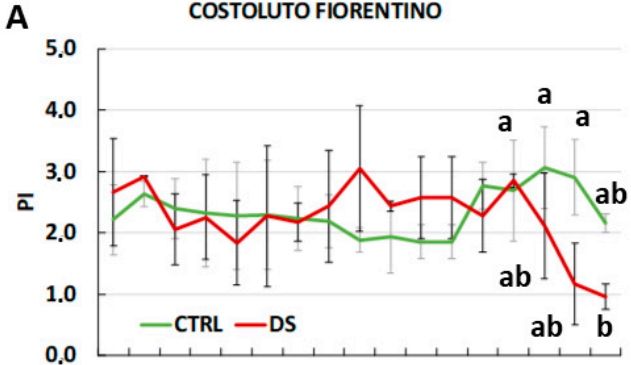

C

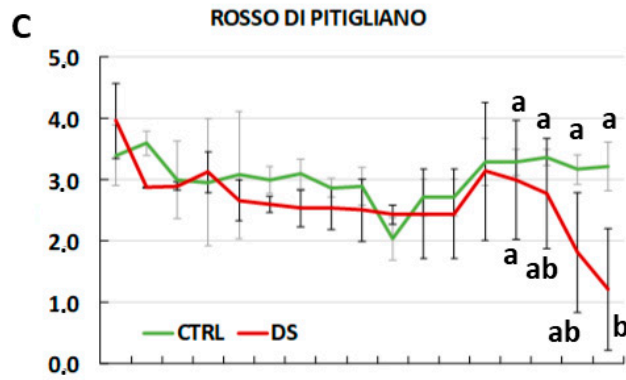

E

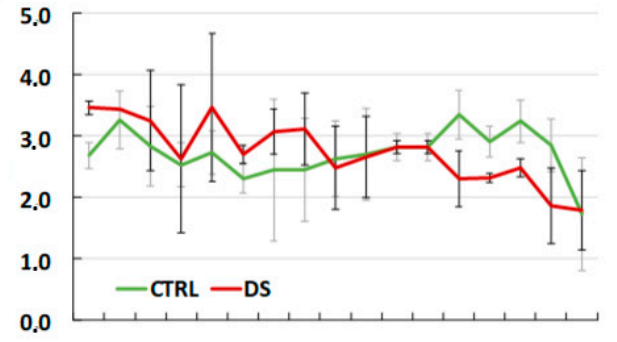

G

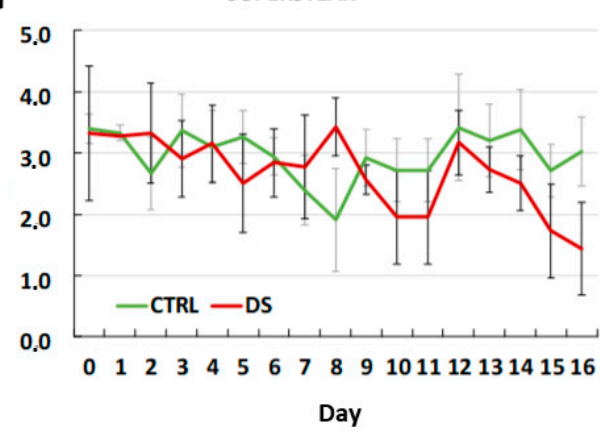

B

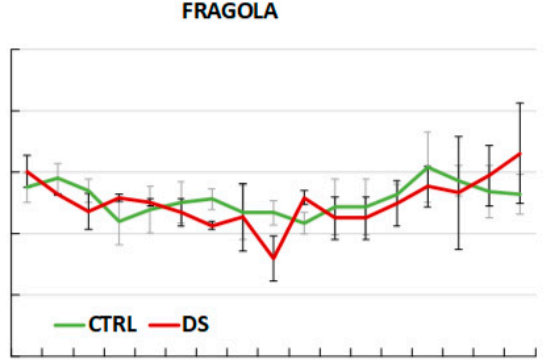

D

CANESTRINO DI LUCCA

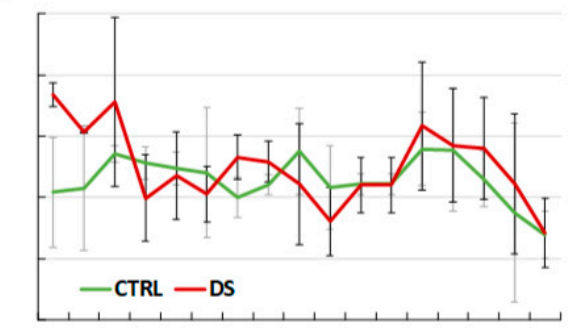

$\mathbf{F}$

QUARANTINO

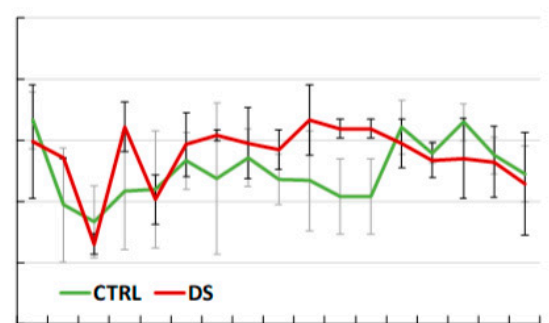

Figure 3. Performance index $\left(\mathrm{PI}_{\mathrm{ABS}}\right)$ in six local varieties $(\mathrm{A}-\mathrm{F})$ and one commercial cultivar 'Supersteak' (G) of tomato (Solanum lycopersicum L.) subjected to drought stress (no water for 16 days) relative to the controls (regularly well-watered plants). Two-way factorial ANOVA followed by Tukey post-hoc test was used to determine the statistical significance of differences. Points with the same lower-case letters do not differ significantly $(p>0.05)$. 

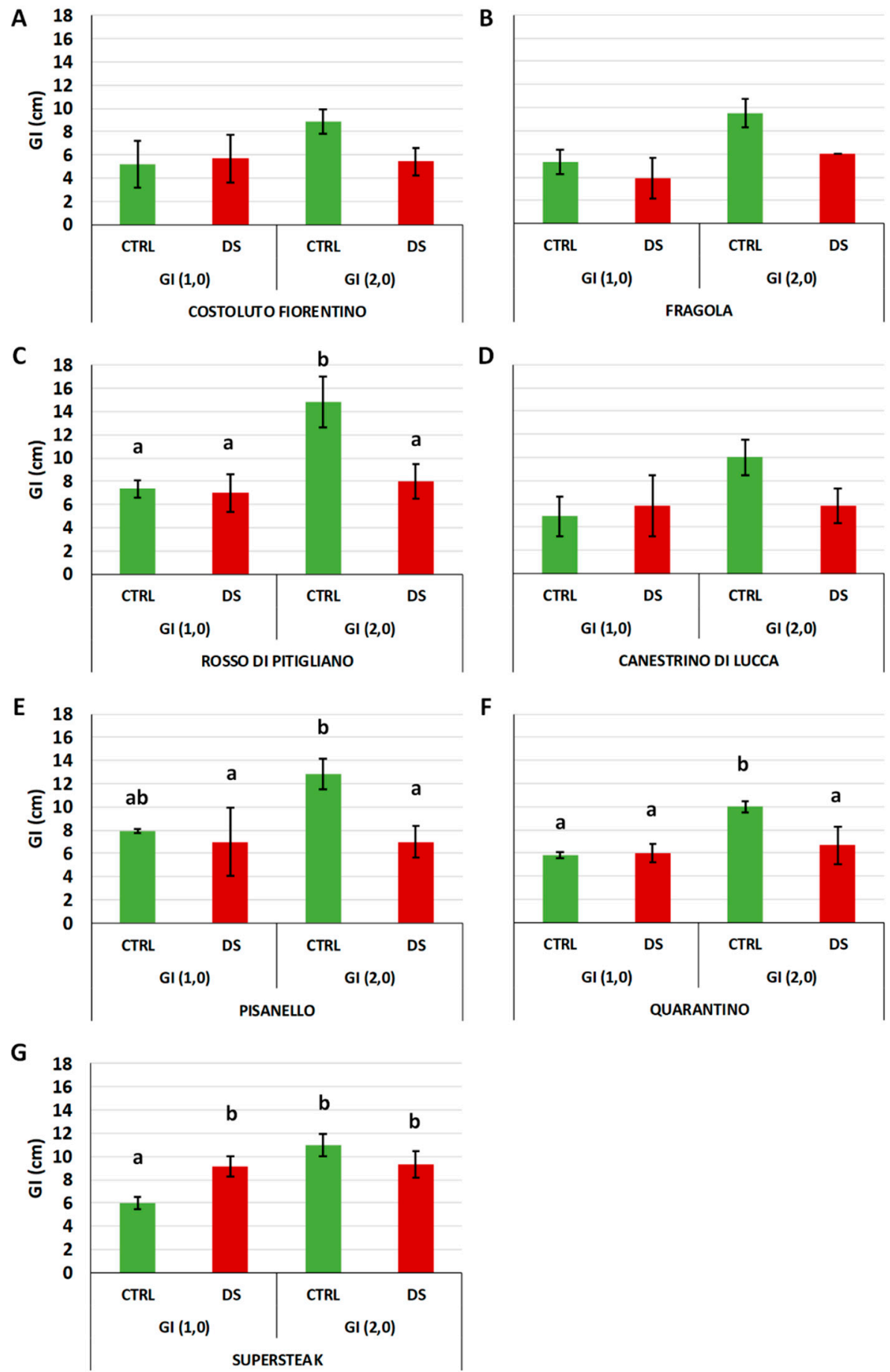

Figure 4. Growth Index (GI) in six local varieties (A-F) and one commercial cultivar 'Supersteak' (G) of tomato (Solanum lycopersicum L.) subjected to drought stress (no water for 16 days) relative to the controls (regularly well-watered plants). Two-way factorial ANOVA followed by Tukey post-hoc test was used to determine the statistical significance of differences. Points with the same lower-case letters do not differ significantly $(p>0.05)$. GI $(1,0)=\left(h_{1}-h_{0}\right) / 2 ;$ GI $(2,0)=\left(h_{2}-h_{0}\right) / 2$.

While GI is indicative of stress, stem diameter cannot be considered a discriminating parameter. In this regard, the results at $t_{0}$ and $t_{1}$ (Figure 5 ) showed that well-irrigated and stressed varieties were still similar while at $t_{2}$ a slight drop in diameter for all varieties was observed. 
A

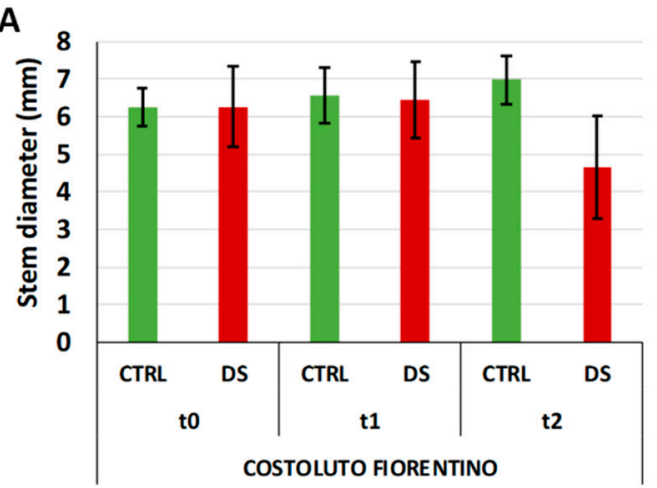

C

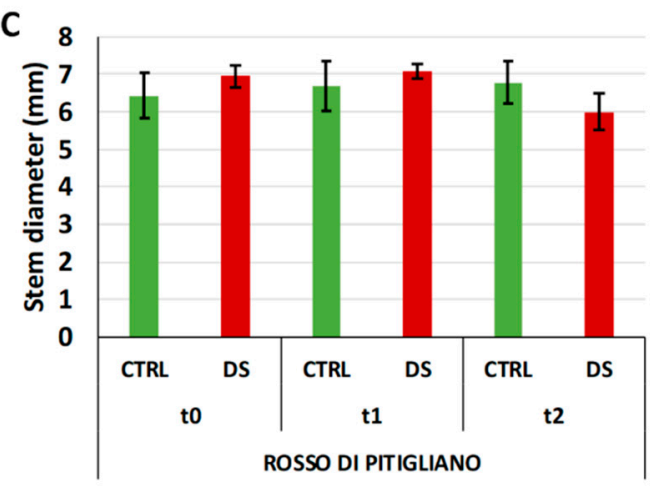

E

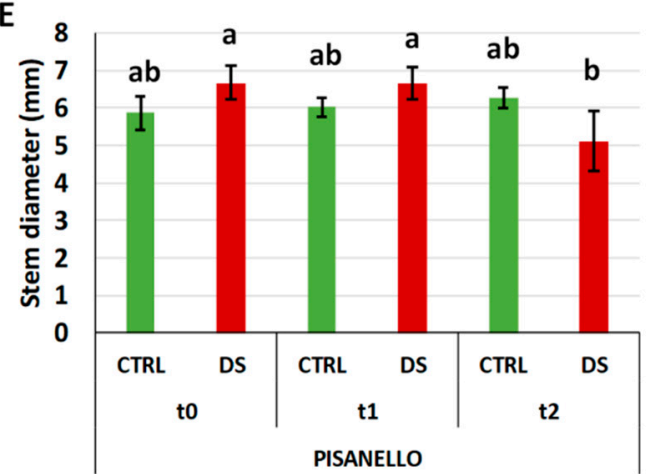

G

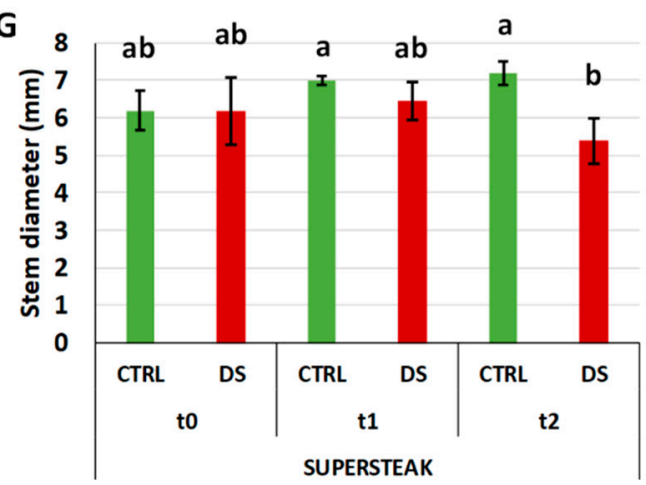

B

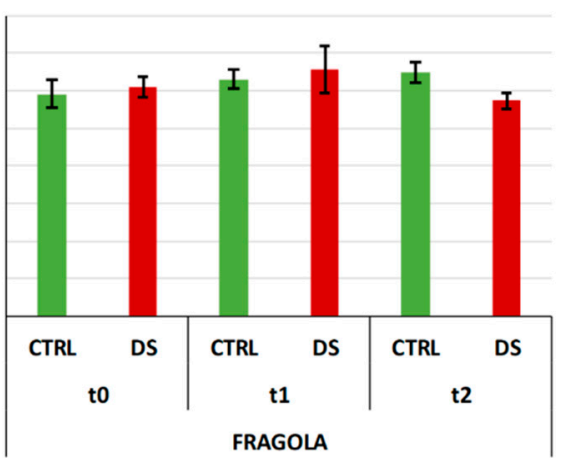

D

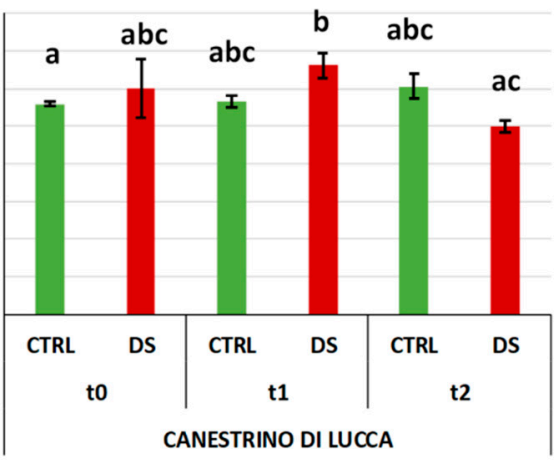

$\mathbf{F}$

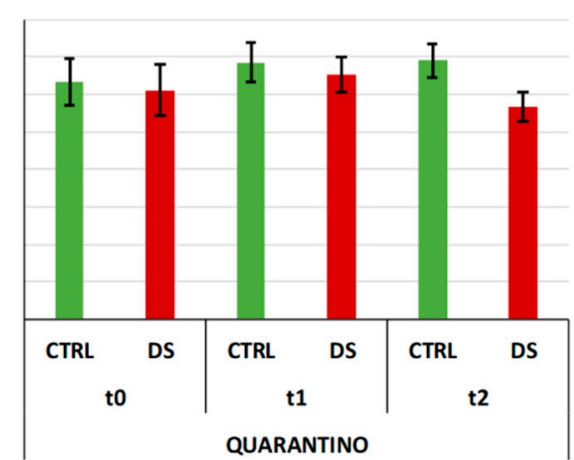

Figure 5. Stem diameter in six local varieties (A-F) and one commercial cultivar 'Supersteak' (G) of tomato (Solanum lycopersicum L.) subjected to drought stress (no water for 16 days) relative to the controls (regularly well-watered plants). Two-way factorial ANOVA followed by Tukey post-hoc test was used to determine the statistical significance of differences. Points with the same lower-case letters do not differ significantly $(p>0.05)$.

Overall, these results together with the phenotypic evaluation allowed us to define the most resistant variety ('Fragola') and the most susceptible ('Pisanello') on which to focus the analyses which 
follow. To highlight differences with commercial cultivars, we also included the 'Supersteak' cultivar in the analysis.

First, a morphological analysis of leaf structure was performed at $t_{2}$ to understand if the impairment of photosynthesis efficiency could be associated with a cytological alteration of leaf tissues. In agreement with the above reported results indicating 'Fragola' (Figure 6A,B) as the most resistant genotype, cellulose staining showed that the general structure of leaves was maintained under drought stress condition: it was still possible to distinguish the palisade parenchyma (PP) and cells retained their typical shape. However, slight damage was detected at the level of spongy parenchyma (SP), with cells approaching each other and leaving few intercellular spaces. A more severe alteration of leaf cytological structure was observed in 'Pisanello' (Figure 6C,D) where it was no longer possible to distinguish between palisade parenchyma and a spongy one and cells no longer had a well-defined shape and were remarkably close to each other. Similar to what was observed for 'Pisanello', 'Supersteak' (Figure 6 E,F) showed a general disorganization of leaf structure: stressed plants exhibited only partially the palisade parenchyma with cells very close to each other, causing the loss of the typical structure of spongy parenchyma, as opposed to that found in the control where palisade cells are well organized, and the spongy parenchyma shows the typical intercellular spaces. Our results agree with that reported for other plants such as olive [33] and blackberry [34] in which a profound rearrangement of leaf architecture has been described. In olive, the authors reported a decrease of the size of both epidermal and mesophyll cells and a corresponding reduction in the mesophyll intercellular space volume that could be interpreted as a strategy to block the movement of water vapor. Zhang et al., 2017 [34] showed that in blackberry the total leaf transections and the upper and lower leaf epidermis declined due to continuous water deficit while the cell walls of upper and lower epidermis and the spongy tissue cell walls were clearly thickened: such thickness of the leaf cuticle was interpreted as a clear indication of drought tolerance.

In addition to analyzing leaf morphology, we also measured other parameters related to the leaf including leaf area (LA), lamina length $(\mathrm{LaL})$, and lamina width $(\mathrm{LaW})$. As shown in Figure 7, at $t_{0}$ and $t_{1}$ the leaf areas of well-irrigated and stressed plants were comparable for all three varieties. At $t_{2}$, some differences could be appreciated; in particular the leaf area of 'Pisanello' and 'Supersteak' varieties decreased in comparison to well irrigated plants although the $p$ values for the differences are slightly above the significance level ( $p=0.07$ and $p=0.08$ respectively). The 'Fragola' variety, on the contrary, was not particularly damaged and, consequently, the leaf area remained similar for both stressed and control plants. The results of leaf morphology were further confirmed by the length of the LaL and leaf width LaW. As for LaL (Figure 8A) and LaW (Figure 8B), these measurements did not show differences at both $t_{0}$ and $t_{1}$ between control and stressed plants, suggesting that in the middle of the stress period $\left(t_{1}\right)$ the tomato varieties did not show severe damage as regards morphometric measurements of leaves. At $t_{2}$, both LaL and LaW were severely reduced in 'Pisanello'. Conversely, in 'Fragola', for which the photosynthetic process was not damaged by the lack of water, leaf area and related parameters were not affected. Based on these results, we hypothesize that the 'Fragola' variety succeeds in carrying out the photosynthetic process even in the presence of reduced availability of water. Our results agree with Liu and Stützel, 2004 [35] who reported a reduction in leaf area and leaf dry mass ratio. The same authors also describe a simultaneous increase in root dry mass ratio indicating that under water deficiency plants invest energy in the enhancement of root system in order to absorb water more efficiently. Similar results were also reported for Populus [36], soybean [37], and other species [4]. 

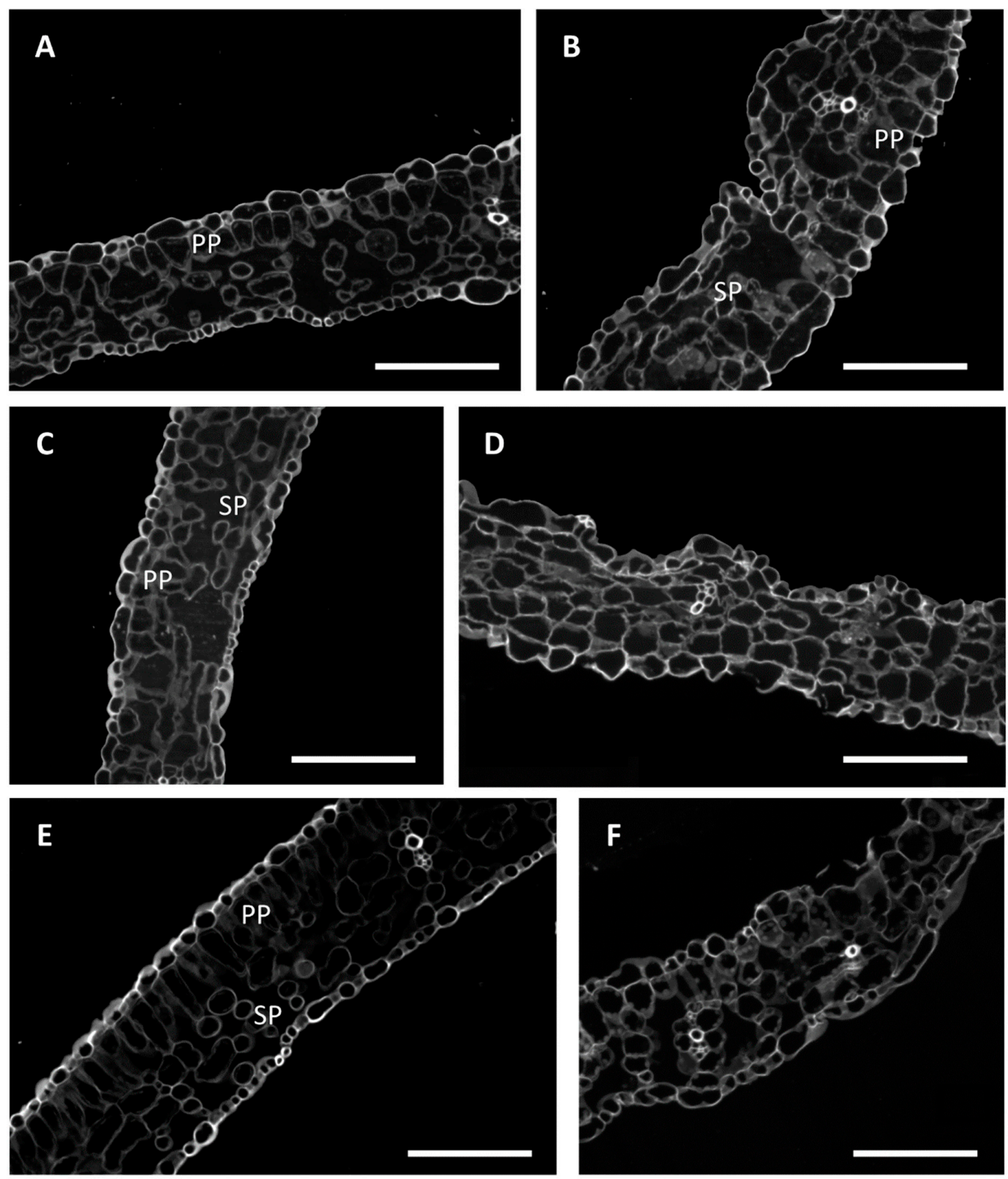

Figure 6. Calcofluor White (CFW) staining in leaves of two local varieties (A,B-'Fragola'; C,D-'Pisanello') and one commercial cultivar (E,F-'Supersteak'). A,C,E are the controls (regularly well-watered plants) and B,D,F are the stressed (no water for 16 days). PP, palisade parenchyma; SP, spongy parenchyma. Scale bar: $100 \mu \mathrm{m}$. 


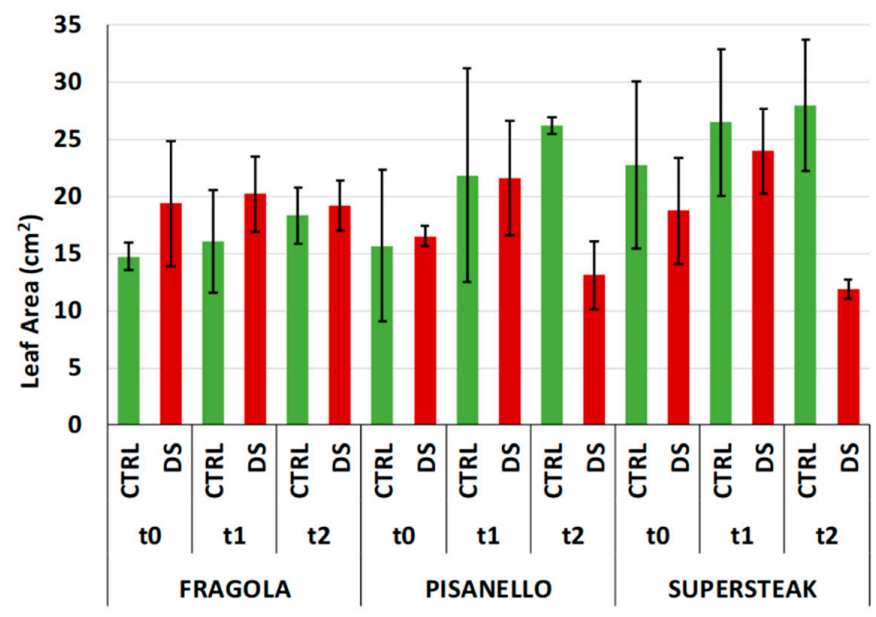

Figure 7. Leaf Area in two local varieties ('Fragola' and 'Pisanello') and one commercial cultivar 'Supersteak' of tomato (Solanum lycopersicum L.) subjected to drought stress (no water for 16 days) relative to the controls (regularly well-watered plants). Two-way factorial ANOVA followed by Tukey post-hoc test was used to determine the statistical significance of differences. Points with the same lower-case letters do not differ significantly $(p>0.05)$. The $\mathrm{p}$-values for 'Pisanello' and 'Supersteak' are near to significance, respectively $p=0.07$ and $p=0.08 . \mathrm{t}_{0}=$ before the start of treatment, $\mathrm{t}_{1}=$ half duration of the stress, $t_{2}=$ the end of the stress.
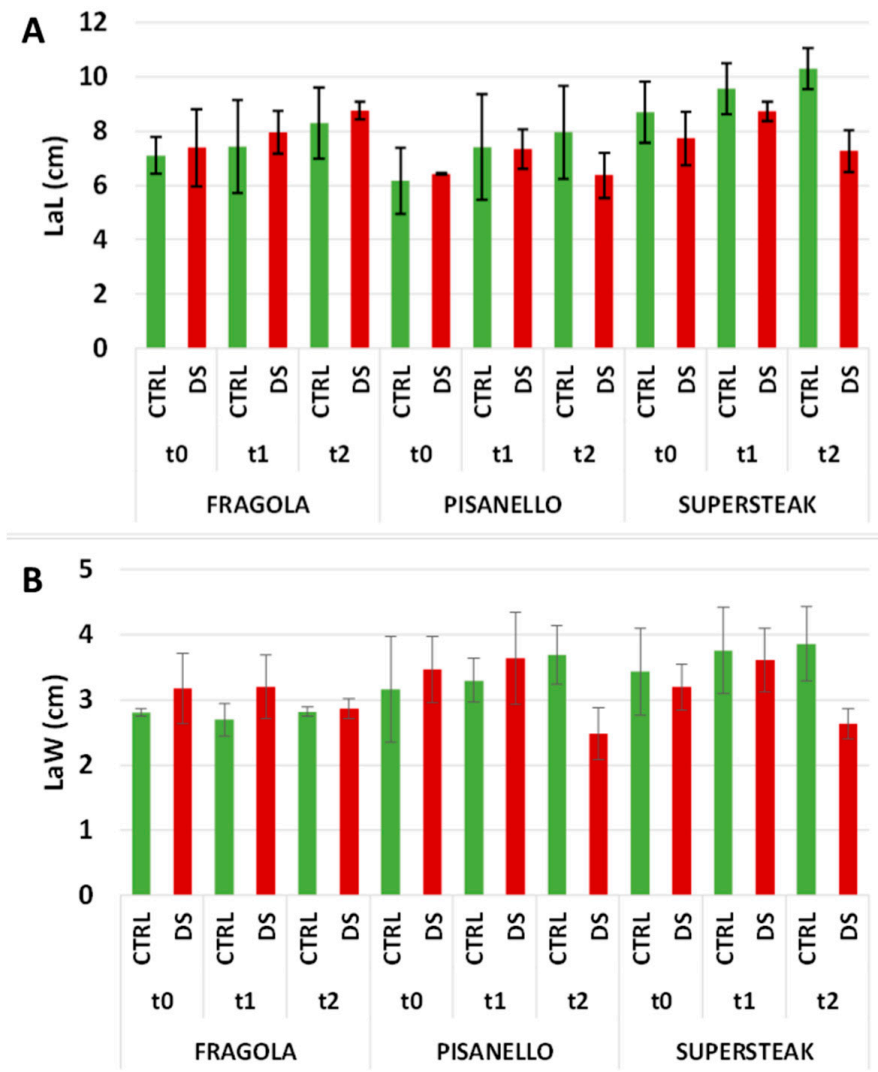

Figure 8. (A) LaL (Lamina Length) and (B) LaW (Lamina Width) in two local varieties ('Fragola' and 'Pisanello') and one commercial cultivar 'Supersteak' of tomato (Solanum lycopersicum L.) subjected to drought stress (no water for 16 days) relative to the controls (regularly well-watered plants). Two- way factorial ANOVA followed by Tukey post-hoc test was used to determine the statistical significance of differences. Points with the same lower-case letters do not differ significantly $(p>0.05) . \mathbf{t}_{0}=$ before the start of treatment, $t_{1}=$ half duration of the stress, $t_{2}=$ the end of the stress. 
Another response that plants can put in place to response to drought stress is the regulation of stomata number and activity [5]. In the case of drought stress, plants close the stomata to limit water loss due to evapotranspiration. Even the stomata number and size are affected by stress: increasing the intensity of water stress generally increases the stomata density and reduces the size of the stomata [6]. These modifications have been interpreted as adaptations to drought as the increase in stomata number also increases the supply of $\mathrm{CO}_{2}$ to leaves while size reduction limits the loss of water. In the present manuscript, the 'Pisanello' and the commercial genotype 'Supersteak' increase the stomata density as a response to stress, while the 'Fragola' variety decreased stomata density in respect to well-watered plants suggesting that 'Fragola' does not perceive the lack of water as stress (Figure 9). Another possible explanation is that a reduction in stomata density implies a limitation of water loss. Our results are in agreement with a recent study in rice showing that transgenic plants with a reduced stomatal density (and a consequent low stomatal conductance) were more able to conserve water. The authors also reported that such plants had equivalent or even higher yields under water lack condition and they concluded that a reduced stomata density is a useful trait, to have plants that better perform in the climate change scenario [38].

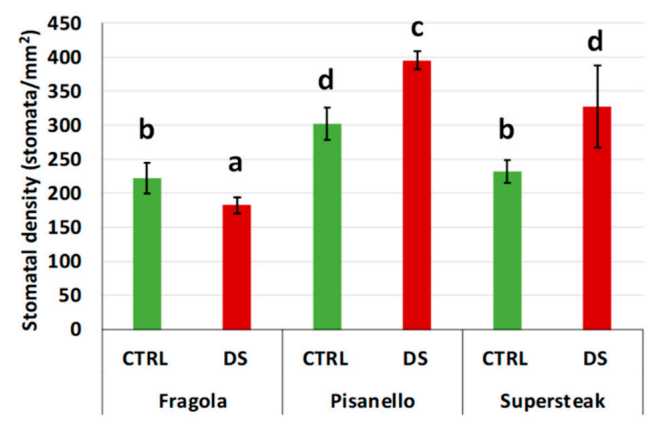

Figure 9. Stomatal density in two local varieties ('Fragola' and 'Pisanello') and one commercial cultivar 'Supersteak' of tomato (Solanum lycopersicum L.) subjected to drought stress (no water for 16 days) relative to the controls (regularly well-watered plants). Two-way factorial ANOVA followed by Tukey post-hoc test was used to determine the statistical significance of differences. Points with the same lower-case letters do not differ significantly $(p>0.05)$.

As mentioned above, the closure of stomata in response to stress can lead to a decrease in $\mathrm{CO}_{2}$ and an increase of $\mathrm{O}_{2}$, thus to an imbalance of electrons in the photosynthetic system with the consequent formation of reactive oxygen species (ROS) [9]. The increase in ROS amount can lead to oxidative stress, capable of damaging various cellular structures [7]. In response, cells put in place scavenging mechanisms to reduce the extent of damage [10]. In the present work, we investigated the distribution of superoxide radicals in the leaves of selected varieties. As shown in Figure 10 the superoxide radicals visible as blue/purple after Nitro Blue Tetrazolium (NBT) staining were found especially in the vascular bundles or in their proximity. 'Fragola' (Figure 10A) and 'Supersteak' (Figure 10C) do not accumulate superoxide radicals under drought stress: only a less intense staining is visible close to the principal leaf vein. On the contrary, in 'Pisanello' (Figure 10B) superoxide radicals are more widely distributed in the leaf: NBT staining not only labeled the veins but also the leaf basal lamina.

The production of reactive oxygen species can induce as response the synthesis of antioxidant molecules. Figure 11A reports the total antioxidant power, expressed as mmol/100 g. 'Fragola' did not increase the antioxidant capacity, which remained at the same level as the control. On the other hand, 'Supersteak' and 'Pisanello' greatly increased the antioxidant ability even more, a symptom of a response to oxidative stress. These data were also confirmed by the total content of polyphenols and flavonoids expressed as mg/100g (Figure 10B,C). Once again, stressed plants of 'Fragola' were comparable to control while in the stressed plants of 'Pisanello' and 'Supersteak' the content of polyphenols and flavonoids increased. We can, therefore, assume that the 'Fragola' variety does not undergo oxidative stress, at least not as substantially as to require the production of antioxidants. 
Our results are in agreement with other papers that report an increment in polyphenols and flavonols under drought stress condition. For example, in tea such an increase has been viewed as a possible marker of drought resistance where resistant clones showed a high content of polyphenols with a low content of water in the soil [39]. In addition to this, the increase would be useful as a strategy to enhance the nutritional and bioactive properties of plants as suggested for Amaranthus [40].
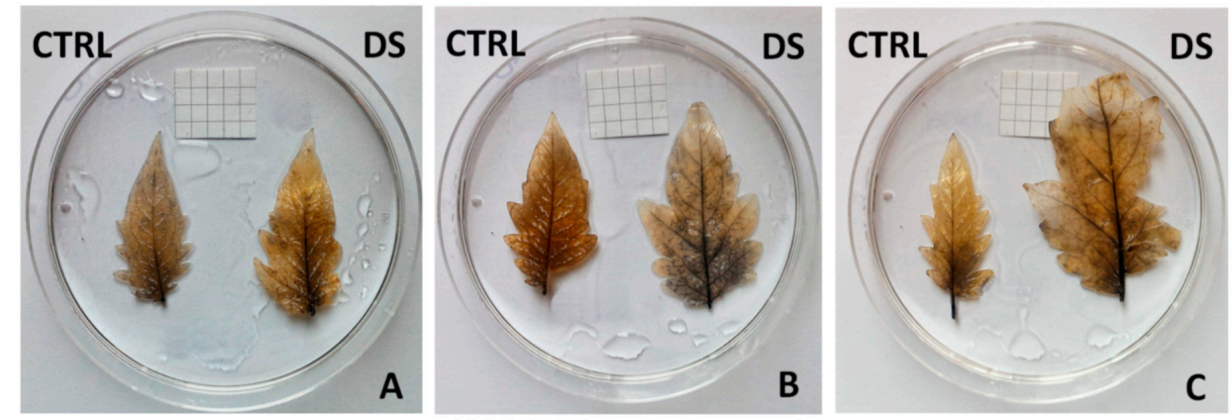

Figure 10. Nitro Blue Tetrazolium (NBT) staining in leaves of two local varieties (A-'Fragola'; B-'Pisanello') and one commercial cultivar (C-'Supersteak'). On the left are the controls (regularly well-watered plants) and on the right are the stressed samples (no water for 16 days). The side of the square in the background is $0.5 \mathrm{~mm}$.

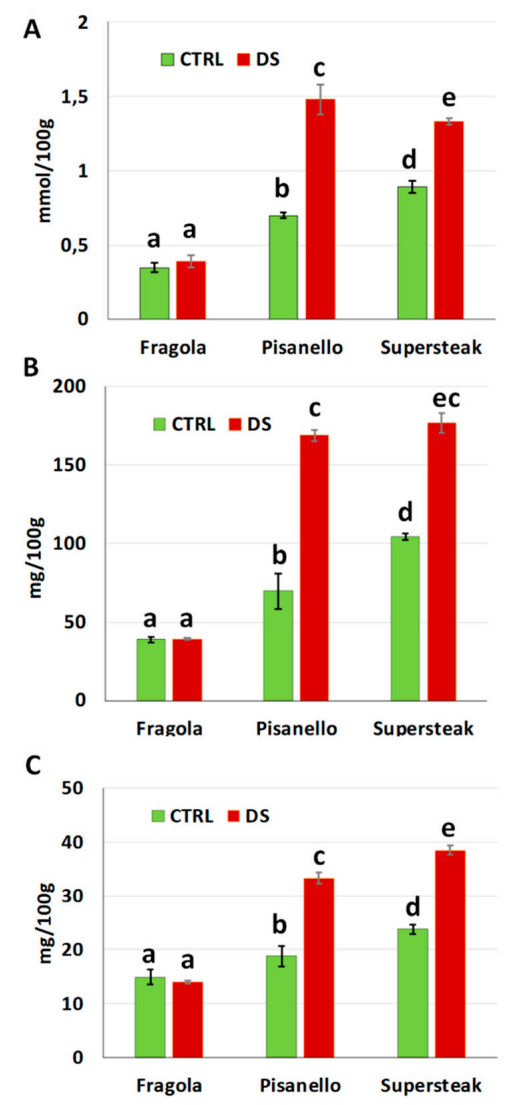

Figure 11. (A) total antioxidant content, (B) polyphenols content and (C) flavonoids content of two local varieties ('Fragola' and 'Pisanello') and one commercial cultivar ('Supersteak') of tomato (Solanum lycopersicum L.) subjected to drought stress (no water for 16 days) relative to the controls (regularly well-watered plants). Two-way factorial ANOVA followed by Tukey post-hoc test was used to determine the statistical significance of differences. Points with the same lower-case letters do not differ significantly $(p>0.05)$. 


\section{Materials and Methods}

\subsection{Plant Material}

Seeds of six tomato local varieties namely: 'Costoluto Fiorentino', 'Fragola', 'Rosso di Pitigliano', 'Canestrino di Lucca', 'Pisanello', and 'Quarantino' were retrieved from the Regional Bank of the Germplasm, while seeds of the commercial cultivar 'Supersteak' (producer company: Royal Seeds ${ }^{\circledR}$ s.r.1., Mirandola, Italy) were purchased at large retailers. 'Supersteak' was chosen among the many commercial tomato cultivars because it is a vigorous and robust plant which is also resistant to common soil diseases.

\subsection{Genetic Characterization of Tomato Local Varieties by SSRs}

Genetic characterization was performed for all the listed varieties. Genomic DNA was isolated from $100 \mathrm{mg}$ of frozen young leaves using the DNeasy ${ }^{\circledR}$ Plant Mini Kit (QIAGEN ${ }^{\circledR}$, Hilden, Germany). DNA extracted from tomato leaves was used to amplify a set of 16 SSR markers selected from the literature (Table S1). PCR assays were performed using the protocols reported in the literature [27-29]. All PCR reactions were carried out using Eppendorf Mastercycler ${ }^{\circledR}$ epGradient. Each PCR reaction was performed in a final volume of $25 \mu \mathrm{L}$ containing: $1 \mathrm{U}$ of DreamTaq DNA Polymerase (ThermoFisher, Waltham, MA, USA), $0.5 \mu \mathrm{L} 10 \mathrm{~mm}$ dNTP mix (ThermoFisher, Waltham, Massachusetts, USA), $0.25 \mu \mathrm{mol} / \mathrm{L}$ of each primer (Sigma-Aldrich, Saint Louis, MO, USA), 1× DreamTaq reaction buffer (ThermoFisher, Waltham, MA, USA), and $30 \mathrm{ng}$ of genomic DNA. The PCR amplification program was: $94{ }^{\circ} \mathrm{C}$ for $2 \mathrm{~min}$ (DNA denaturation), 40 cycles with $94{ }^{\circ} \mathrm{C}$ for $45 \mathrm{~s}$ (denaturation); Ta for $45 \mathrm{~s}$ (annealing) where Ta changes for each primer pair; $72{ }^{\circ} \mathrm{C}$ for $45 \mathrm{~s}$ (extension) and a final extension at $72{ }^{\circ} \mathrm{C}$ for $7 \mathrm{~min}$. After amplification, PCR products were analyzed by electrophoresis on $1.8 \%$ agarose gel run with $1 \times$ TBE ( $89 \mathrm{mmol} / \mathrm{L}$ Tris borate, $89 \mathrm{mmol} / \mathrm{L}$ boric acid, $2 \mathrm{mmol} / \mathrm{L} \mathrm{EDTA}$ ) at $80 \mathrm{~V}$.

\subsection{Growth Conditions and Stress Treatment}

Seeds of each variety were first germinated in Petri dishes with filter paper soaked with distilled water at a constant temperature of $25^{\circ} \mathrm{C}$ in the dark. Afterwards, the seedlings were transferred to a cultivation chamber in a tray with wells (each well $4 \times 5 \times 6 \mathrm{~cm}$ ) at a constant temperature of $25^{\circ} \mathrm{C}$ with a $14 \mathrm{~h} / 10 \mathrm{~h}$ light/darkness photoperiod with a PPFD (photosynthetic photon-flux density) of $350 \mu \mathrm{mol}$ $\mathrm{m}^{-2} \mathrm{~s}^{-1}$ and with relative humidity of $50 \pm 10 \%$. Then two-leaf seedlings were moved into pots larger than $10 \times 10 \times 12 \mathrm{~cm}$ at the same growth conditions previously described. The substrate used for repotting operations was the VIGOR PLANT ${ }^{\circledR}$ GROWING MEDIUM, Professional Mix. All plants were well-watered until the beginning of the water stress treatment maintaining water availability close to the capacity of the potting mix. The water-stress treatment began when plants were $30 / 40 \mathrm{~cm} \mathrm{high}$ corresponding to 45 days after germination and was maintained for 16 days while the control group (CTRL) was kept in full irrigated regime. The duration of drought treatment was chosen in agreement with Landi et al., 2016 and Sánchez-Rodríguez et al., 2010 [41,42]. For each genotype, measurements were done on three control plants vs. three drought-stressed plants.

\subsection{Determination of the Efficiency of Photosynthesis $\left(F_{v} / F_{m}\right.$ and PI)}

Photosynthetic efficiency was evaluated by using the Fluorometer Handy PEA 2000 (Hansatech Instruments King's Lynn, Norfolk, UK). For each genotype, the values of $\mathrm{F}_{\mathrm{v}} / \mathrm{F}_{\mathrm{m}}$ and PI were collected daily for 16 days to identify the time when plants begin to perceive water stress. The following equations were used to calculate $\mathrm{F}_{\mathrm{v}} / \mathrm{F}_{\mathrm{m}}(1)$ and PI (2) parameters [43]:

$$
\begin{gathered}
\mathrm{F}_{\mathrm{v}} / \mathrm{F}_{\mathrm{m}}=\left(\mathrm{F}_{\mathrm{m}}-\mathrm{F}_{0}\right) / \mathrm{F}_{\mathrm{m}} \\
\mathrm{PI}_{\mathrm{ABS}}=\frac{1-\left(\frac{\mathrm{F}_{0}}{\mathrm{~F}_{\mathrm{m}}}\right)}{\mathrm{M}_{0} / \mathrm{V}_{\mathrm{j}}} \times \frac{\mathrm{F}_{\mathrm{m}}-\mathrm{F}_{0}}{\mathrm{~F}_{0}} \times \frac{1-\mathrm{V}_{\mathrm{j}}}{\mathrm{V}_{\mathrm{j}}}
\end{gathered}
$$


where $F_{m}$ is the maximum fluorescence value, $F_{0}$ is fluorescence value at zero instant, $F_{v}$ is the difference between $\mathrm{F}_{\mathrm{m}}$ and $\mathrm{F}_{0}, \mathrm{~V}_{\mathrm{J}}$ is relative $\mathrm{F}_{\mathrm{v}}$, and $\mathrm{M}_{0}$ is the initial slope of fluorescence kinetics. $\mathrm{F}_{\mathrm{v}} / \mathrm{F}_{\mathrm{m}}$, therefore, is an index from the maximum value of 1.00 , equivalent to $100 \%$ of the maximum photochemical efficiency of photosystem II. Performance index (PI), a more sensitive parameter showing variations of the entire photosynthetic apparatus, including photosystem I (PSI) and II (PSII). $\mathrm{F}_{\mathrm{v}} / \mathrm{F}_{\mathrm{m}}$ and PI were measured for each genotype (1-7) in 3 plants over 16 days. Results are expressed as the average of the three replicas \pm the standard deviation.

\subsection{Measurement of Stem Diameter and Plant Growth}

For each genotype, measures of stem diameter and growth were performed at time $t_{0}$ (before the start of treatment), at time $t_{1}$ (half duration of the stress -8 days without water) and at time $t_{2}$ (at the end of the stress). Stem diameter at the bottom of plant was measured via a digital gauge (Powerfix ${ }^{\circledR}$, Neckarsulm, Germany) and plant height, used for the estimation of growth index (GI) (3), was measured by a meter stick. The formula used to calculate GI was:

$$
\mathrm{GI}_{\mathrm{f}, \mathrm{i}}=\mathrm{h}_{\mathrm{f}}-\mathrm{h}_{\mathrm{i}} / 2
$$

where $h_{f}$ is final height (at time $t_{1}$ or time $t_{2}$ ) and hi is initial height (at time $t_{0}$ ). Thus, this was summarized as $\mathrm{GI}_{1,0}$ the Growth Index between $t_{1}$ and $t_{0}, \mathrm{GI}_{2,0}$ that between $t_{2}$ and $\mathrm{t}_{0}$. Height and stem diameter were measured for each genotype (1-7) in 3 plants in three timing points. For the height the Growth Index (GI) was calculated and the standard deviation was then computed by the error propagation. Results are expressed as the average of the three replicas \pm the standard deviation.

\subsection{Morphometric and Histological Evaluation of Leaves}

The morphometric parameters used to evaluate leaves were leaf area (LA), lamina length (LaL), and lamina width $(\mathrm{LaW})$. All these parameters were calculated for each variety to the same timing points $\left(t_{0}, t_{1}, t_{2}\right)$. At each interval, photos were taken of the leaves at the same developmental stage. Photos were then examined by Image (National Institutes of Health, Bethesda, MD, USA) to determine the LA, LaL, and LaW. LA, LaL, and LaW were measured in 3 plants at three timing points. Results are expressed as the average of the three replicates \pm the standard deviation.

At $t_{2}$, overall leaf structure was analyzed by CFW (Calcofluor White) staining [44]. Leaves were taken at the same developmental stage and cut transversely at the midpoint. Samples were fixed in $2.5 \%$ glutaraldehyde $(w / v)$ in $0.1 \mathrm{M}$ phosphate buffer $(\mathrm{pH} 7.2)$ for $2 \mathrm{~h}$ at room temperature. After that samples were dehydrated in increasing ethanol concentration $(10 \%, 30 \%, 50 \%, 70 \%, 90 \%, 100 \%)$ and then embedded in Technovit 7100 (Kultzer GmbH, Hanau, Germany). Semi-thin sections (4-5 $\mu \mathrm{m}$ ) were obtained with Ultratome NOVA microtome (LKB, Bromma, Sweden). The resulting sections were stained with a $0.1 \%$ CFW solution diluted in distilled water for about $30 \mathrm{~min}$. Slides were washed quickly with distilled water, coated with tin foil to avoid fluorescence decay, and finally put in the stove at $37^{\circ} \mathrm{C}$ for $5 \mathrm{~min}$ to evaporate the excess water. Finally, samples were examined with a fluorescence microscope (Imager. Z1 Apotome Zeiss, Oberkochen, Germany).

\subsection{Stomatal Density}

Stomata density was calculated using the protocol proposed by Xu and Zhou (2008) [6]. Briefly, leaves from each variety, at the time $t_{2}$, were sampled at the same stage of development. A thin layer of transparent nail polish was uniformly applied on the lower surface of leaves and, once dried, it was pulled away. The resulting molds were then examined under the optical microscope (Axiophot Zeiss, Oberkochen, Germany). For each sample, 10 photos were taken, and stomata were counted using ImageJ (National Institutes of Health, Bethesda, MD, USA). Stomata density was expressed as the stomata number per leaf area unit $\left(\right.$ in $\mathrm{mm}^{2}$ ). Stomata number was measured for each genotype 
in 3 plants at the end of stress, totaling 10 photos for each genotype. Results were expressed as the average of the 10 counts \pm the standard deviation.

\subsection{Determination of Superoxide Radicals}

Superoxide radicals in the leaves at $t_{2}$ (after 16 days of drought) were detected by NBT (Nitro Blue Tetrazolium) staining [45]. For each variety leaves at the same stage of development were analyzed. They were incubated in the NBT staining solution $(0.5 \mathrm{mg} / \mathrm{mL})$ for $8 \mathrm{~h}$ at room temperature in darkness and then de-colorized by soaking in ethanol (95\%) for $15 \mathrm{~min}$.

\subsection{Samples Extraction for Colorimetric Analysis}

For sample extraction, $1 \mathrm{~g}$ of leaves (corresponding to 5 leaves) was weighed and crushed in liquid nitrogen. The resulting powder was resuspended in $3 \mathrm{~mL}$ of $70 \%$ acetone, homogenized for 5 min by an Ultra-Turrax ${ }^{\circledR}$ T-25 basic (IKA ${ }^{\circledR}$-Werke GmbH \& Co. KG, Staufen im Breisgau, Germany) and sonicated for about 20 min with Elma Transsonic T 460/H. A second step of homogenization was added to ensure the total lysis of plant material. The final mixture was centrifuged for $5 \mathrm{~min}$ at 4000 r.p.m. (1500 r.c.f.) (Eppendorf ${ }^{\circledR}$ Microcentrifuge 5415D, Hamburg, Germany). Sample extraction was performed for colorimetric analysis using 3 plants. The experiment was conducted in triplicate. Results are expressed as the average of the three replicas \pm the standard deviation.

\subsection{Determination of Antioxidant Power}

Antioxidant power was determined by the FRAP method (Ferric Ion Reducing Antioxidant Power) [46]. For each reaction, $20 \mu \mathrm{L}$ of extract was added to fresh FRAP reagent composed of $2040 \mu \mathrm{L}$ of $300 \mathrm{mM}$ acetate buffer pH 3.6, $200 \mu \mathrm{L}$ of $10 \mathrm{mM}$ TPTZ (2,4,6-tripyridyl-s-triazine) and $200 \mu \mathrm{L}$ of $20 \mathrm{mM}$ ferric chloride $\left(\mathrm{FeCl}_{3}\right)$. Samples were then incubated for $1 \mathrm{~h}$ at $37^{\circ} \mathrm{C}$. The antioxidant power was then measured by UV-Vis spectrophotometer (Double beam Perkin Elmer UV/Visible spectrophotometer, Waltham, MA, USA) sets at a maximum absorption of $593 \mathrm{~nm}$. The absorbance value was interpolated on a standard curve of known solutions of ferrous sulfate. Values were expressed in mmol of ferrous chloride $\left(\mathrm{Fe}^{2+}\right)$ equivalent per $100 \mathrm{~g}$ of leaves.

\subsection{Determination of Phenolic Content}

The content of total polyphenols was determined by the colorimetric assay Folin-Ciocalteu (F-C) [47]. For each reaction, $500 \mu \mathrm{L}$ of extract were added to $3950 \mu \mathrm{L}$ of distilled water, $250 \mu \mathrm{L}$ of F-C reagent (Sigma Chemical, St. Louis, Missouri, USA), and $750 \mu \mathrm{L}$ of a sodium carbonate saturated solution $\left(\mathrm{Na}_{2} \mathrm{CO}_{3}\right)$. Samples were then incubated at $37^{\circ} \mathrm{C}$ for $30 \mathrm{~min}$. The absorbance was recorded by UV-Vis spectrophotometer (Double beam Perkin Elmer UV/Visible spectrophotometer, Waltham, Massachusetts, USA) at $795 \mathrm{~nm}$. The spectrophotometric results were compared to a pre-made gallic acid standard (Sigma Chemical, St. Louis, Missouri, USA) curve. Total phenolic content was expressed as $\mathrm{mg}$ of gallic acid equivalents (GAE) per $100 \mathrm{~g}$ of leaves.

\subsection{Determination of Flavonoid Content}

The content of flavonoids was determined by the aluminum chloride method [48]. Briefly, $500 \mu \mathrm{L}$ of extract were added to $1500 \mu \mathrm{L}$ of $95 \%$ ethanol, $100 \mu \mathrm{L}$ of $10 \%$ aluminum chloride solution $\left(\mathrm{AlCl}_{3}\right)$, $100 \mu \mathrm{L}$ of $1 \mathrm{M}$ potassium acetate solution $\left(\mathrm{CH}_{3} \mathrm{CO}_{2} \mathrm{~K}\right)$ and $2800 \mu \mathrm{L}$ of distilled water. The obtained solution was left $30 \mathrm{~min}$ at room temperature. After incubation, absorbance was recorded by UV-Vis spectrophotometer (Double beam Perkin Elmer UV/Visible spectrophotometer, Waltham, Massachusetts, USA) set at $415 \mathrm{~nm}$. Total flavonoid content was calculated in relation to a quercetin standard (Sigma Chemical, St. Louis, Missouri, USA) from a calibration curve and values were expressed as mg of quercetin equivalents (QeE) per $100 \mathrm{~g}$ of leaves. 


\subsection{Statistical Analysis}

The normal distribution of data of the measured parameters was assessed by Kolmogorov-Smirnov and Shapiro-Wilk tests. Data of stem diameter were squared transformed while data of growth index, stomatal density, and lamina width were log10-transformed to achieve normality. For each genotype differences in the measured parameters (unless antioxidant power, phenolic and flavonoid content, see below) between the two treatments (control and drought stress) over time (days) were analyzed by two-way-factorial ANOVA followed by Tukey HSD test for multiple comparison of means. Data about the antioxidant power, phenolic and flavonoid content were tested as well by two-way factorial ANOVA followed by Tukey HSD test for the evaluation of differences between treatments and genotypes. All statistics were performed using STATISTICA with the $\alpha$-error set at 0.05 .

\section{Conclusions}

In conclusion, the analyses carried out in this study indicate that locally adapted tomato varieties exhibit a genotype-dependent response to drought. Our research is one of the few examples of studies on the effects of water stress on the vegetative growth of local Italian tomato varieties. Considering them collectively, our data show that the existence of a genotype-dependent response that may explain the different degree of tolerance to drought as observed among the varieties analyzed. We can therefore assume that the variety 'Fragola', classified as the most resistant genotype, upon perceiving the lack of water activates all possible mechanisms capable of preventing water loss: it reduces the number of stomata and, consequently, the water loss. In addition to this, we also observed a proper functioning of the photosynthetic apparatus (as demonstrated by the $\mathrm{F}_{\mathrm{v}} / \mathrm{F}_{\mathrm{m}}$ and PI values). The correct activity of photosynthetic apparatus also may explain why in 'Fragola' the production of ROS is limited and not sufficient to damage it. Moreover, the level of antioxidant molecules, associated with oxidative stress, is still comparable to well-irrigated plants. This would indicate that 'Fragola' has a very efficient enzymatic system of ROS scavenging that maintains the level of antioxidants comparable to well irrigated plants. This hypothesis is supported by evidence that enhancing the activities of antioxidant enzymes and/or accumulating low-Mr antioxidants by genetic manipulation increases tolerance of plant varieties to stresses through more efficient removal of ROS [49]. As a consequence of the correct functioning of the photosynthetic apparatus, all processes related to vegetative growth (e.g., plant height, leaf area, LaW, and LaL) are not compromised. On the contrary, the variety 'Pisanello' was proven to be the most susceptible: the variety attempts to implement a series of responses (such as variation of stomata density or anti-oxidant response); however, this variety is severely affected, suggesting that the mechanisms adopted are not sufficient to counteract the damage. This study therefore enables the discrimination of local tomato varieties exposed to water stress, suggesting the existence of a valuable reservoir of genetic biodiversity with more resistant tomato genotypes, and opening the way to research on the mechanisms of response to drought.

Supplementary Materials: The following are available online at http://www.mdpi.com/2223-7747/8/9/336/s1, Figure S1: Images of regularly irrigated (control, CTRL) and drought-stressed (DS) tomato plants of the varieties 'Costoluto Fiorentino' and 'Fragola', respectively at time $t_{0}$ (before treatment), $t_{1}$ (half treatment) and $t_{2}$ (end of treatment). Squares behind the plants have a side of $10 \mathrm{~cm}$. Figure S2: Images of regularly irrigated (control, CTRL) and drought-stressed (DS) tomato plants of the varieties 'Rosso di Pitigliano' and 'Canestrino di Lucca', respectively at time $t_{0}$ (before treatment), $t_{1}$ (half treatment) and $t_{2}$ (end of treatment). Squares behind the plants have a side of $10 \mathrm{~cm}$. Figure S3: Images of regularly irrigated (control, CTRL) and drought-stressed (DS) tomato plants of the varieties 'Pisanello' and 'Quarantino', respectively at time $\mathrm{t}_{0}$ (before treatment), $\mathrm{t}_{1}$ (half treatment), and $t_{2}$ (end of treatment). The double arrow in $t_{2}$ indicates the difference in height between control and treated plants. Squares behind the plants have a side of $10 \mathrm{~cm}$. Figure S4: Images of regularly irrigated (control, CTRL) and drought-stressed (DS) tomato plants of the commercial variety 'Supersteak', respectively at time $t_{0}$ (before treatment), $t_{1}$ (half treatment), and $t_{2}$ (end of treatment). The double arrow in $t_{2}$ indicates the difference in height between control and treated plants. Squares behind the plants have a side of $10 \mathrm{~cm}$. Table S1: List of primer sequences used for genotyping.

Author Contributions: Formal analysis V.C., L.M., C.F.; data curation V.C., L.M., M.N., M.R., G.C., C.C.; review and editing V.C., L.M., M.R., G.C., C.C.; supervision G.C., C.C. 
Funding: This research received no external funding.

Acknowledgments: We thank the Tuscany Region for supporting the Ph.D. grant of VC in the framework of 'Pegaso'-POR FSE TOSCANA 2014-2020 Program GiovaniSì. We also thank CNR-IBE (Follonica, Italy) for kindly providing the genetic resources used in the present work.

Conflicts of Interest: The authors declare no conflict of interest.

\section{References}

1. Joshi, R.; Wani, S.H.; Singh, B.; Bohra, A.; Dar, Z.A.; Lone, A.A.; Pareek, A.; Singla-Pareek, S.L. Transcription factors and plants response to drought stress: Current understanding and future directions. Front Plant Sci. 2016, 7, 1029. [CrossRef] [PubMed]

2. Dai, A. Increasing drought under global warming in observations and models. Nat. Clim. Chang. 2013, 3, 52-58. [CrossRef]

3. Basu, S.; Ramegowda, V.; Kumar, A.; Pereira, A. Plant adaptation to drought stress. F1000Research 2016, 5, 1554. [CrossRef] [PubMed]

4. Farooq, M.; Wahid, A.; Kobayashi, N.; Fujita, D.; Basra, S.M.A. Plant Drought Stress: Effects, Mechanisms and Management. In Sustainable Agriculture; Springer: Dordrecht, The Netherlands, 2009; pp. 153-188.

5. Pirasteh-Anosheh, H.; Saed-Moucheshi, A.; Pakniyat, H.; Pessarakli, M. Stomatal responses to drought stress. In Water Stress and Crop Plants; Wiley: Hoboken, NJ, USA, 2016; pp. 24-40.

6. Xu, Z.; Zhou, G. Responses of leaf stomatal density to water status and its relationship with photosynthesis in a grass. J. Exp. Bot. 2008, 59, 3317-3325. [CrossRef] [PubMed]

7. Das, K.; Roychoudhury, A. Reactive oxygen species (ROS) and response of antioxidants as ROS-scavengers during environmental stress in plants. Front. Environ. Sci. 2014, 2, 53. [CrossRef]

8. Gill, S.S.; Tuteja, N. Reactive oxygen species and antioxidant machinery in abiotic stress tolerance in crop plants. Plant Physiol. Biochem. 2010, 48, 909-930. [CrossRef]

9. Cruz de Carvalho, M.H. Drought stress and reactive oxygen species. Plant Signal Behav. 2008, 3, $156-165$. [CrossRef]

10. Singh, R.; Singh, S.; Parihar, P.; Mishra, R.K.; Tripathi, D.K.; Singh, V.P.; Chauhan, D.K.; Prasad, S.M. Reactive oxygen species (ROS): Beneficial companions of plants' developmental processes. Front Plant Sci. 2016, 7, 1299. [CrossRef]

11. Perveen, R.; Suleria, H.A.R.; Anjum, F.M.; Butt, M.S.; Pasha, I.; Ahmad, S. Tomato (Solanum lycopersicum) carotenoids and lycopenes chemistry; metabolism, absorption, nutrition, and allied health claims-A comprehensive review. Crit. Rev. Food Sci. Nutr. 2015, 55, 919-929. [CrossRef]

12. Kissoudis, C.; Sunarti, S.; Van de Wiel, C.; Visser, R.G.F.; van der Linden, C.G.; Bai, Y. Responses to combined abiotic and biotic stress in tomato are governed by stress intensity and resistance mechanism. J. Exp. Bot. 2016, 67, 5119-5132. [CrossRef]

13. Mareri, L.; Faleri, C.; Romi, M.; Mariani, C.; Cresti, M.; Cai, G. Heat stress affects the distribution of JIM8-labelled arabinogalactan proteins in pistils of Solanum lycopersicum cv Micro-Tom. Acta Physiol. Plant. 2016, 38, 184. [CrossRef]

14. Bartels, D.; Sunkar, R. Drought and salt tolerance in plants. Crit. Rev. Plant. Sci. 2005, 24, 23-58. [CrossRef]

15. Nuruddin, M.M.; Madramootoo, C.A.; Dodds, G.T. Effects of water stress at different growth stages on greenhouse tomato yield and quality. HortScience 2003, 38, 1389-1393. [CrossRef]

16. Pervez, M.A.; Ayub, C.M.; Khan, H.A.; Shahid, M.A.; Ashraf, I. Effect of drought stress on growth, yield and seed quality of tomato (Lycopersicon esculentum L.). Pak. J. Agric. Sci. 2009, 46, 174-178.

17. Wahb-Allah, M.A.; Alsadon, A.A.; Ibrahim, A.A. Drought tolerance of several tomato genotypes under greenhouse conditions. World Appl. Sci. J. 2011, 15, 933-940.

18. Kirda, C.; Cetin, M.; Dasgan, Y.; Topcu, S.; Kaman, H.; Ekici, B.; Derici, M.R.; Ozguven, A.I. Yield response of greenhouse grown tomato to partial root drying and conventional deficit irrigation. Agric. Water Manag. 2004, 69, 191-201. [CrossRef]

19. Harmanto; Salokhe, V.M.; Babel, M.S.; Tantau, H.J. Water requirement of drip irrigated tomatoes grown in greenhouse in tropical environment. Agric. Water Manag. 2005, 71, 225-242. [CrossRef]

20. Sivakumar, R.; Srividhya, S. Impact of drought on flowering, yield and quality parameters in diverse genotypes of tomato (Solanum lycopersicum L.). Adv. Hortic. Sci. 2016, 30, 3-11. 
21. Mickelbart, M.V.; Hasegawa, P.M.; Bailey-Serres, J. Genetic mechanisms of abiotic stress tolerance that translate to crop yield stability. Nat. Rev. Genet. 2015, 16, 237-251. [CrossRef]

22. Hamada, H.; Kakunaga, T. Potential Z-DNA forming sequences are highly dispersed in the human genome. Nature 1982, 298, 396-398. [CrossRef]

23. Lee, L.S.; Henry, R.J. Commercial applications of plant genotyping. In Plant Genotyping: The DNA Fingerprinting of Plants; CABI Publishing: Wallingford, UK, 2009; pp. 265-273.

24. Abbasov, M.; Akparov, Z.; Gross, T.; Babayeva, S.; Izzatullayeva, V.; Hajiyev, E.; Rustamov, K.; Gross, P.; Tekin, M.; Akar, T.; et al. Genetic relationship of diploid wheat (Triticum spp.) species assessed by SSR markers. Genet. Resour. Crop. Evol. 2018, 65, 1441-1453. [CrossRef]

25. Emebiri, L.C. EST-SSR markers derived from an elite barley cultivar (Hordeum vulgare L. "Morex"): Polymorphism and genetic marker potential. Genome 2009, 52, 665-676. [CrossRef] [PubMed]

26. Gupta, K.; Balyan, S.; Edwards, J.; Isaac, P.; Korzun, V.; Röder, M.; Gautier, M.F.; Joudrier, P.; Schlatter, R.; Dubcovsky, J.; et al. Genetic mapping of 66 new microsatellite (SSR) loci in bread wheat. Theor. Appl. Genet. 2002, 105, 413-422. [CrossRef] [PubMed]

27. Suliman-Pollatschek, S.; Kashkush, K.; Shats, H.; Hillel, J.; Lavi, U. Generation and mapping of AFLP, SSRs and SNPs in Lycopersicon esculentum. Cell Mol. Biol. Lett. 2002, 7, 583-597.

28. Sardaro, M.L.S.; Marmiroli, M.; Maestri, E.; Marmiroli, N. Genetic characterization of Italian tomato varieties and their traceability in tomato food products. Food Sci. Nutr. 2013, 1, 54-62. [CrossRef] [PubMed]

29. He, C.; Poysa, V.; Yu, K. Development and characterization of simple sequence repeat (SSR) markers and their use in determining relationships among Lycopersicon esculentum cultivars. Theor. Appl. Genet. 2003, 106, 363-373. [CrossRef] [PubMed]

30. Gururani, M.A.; Venkatesh, J.; Tran, L.S.P. Regulation of photosynthesis during abiotic stress-induced photoinhibition. Mol. Plant. 2015, 8, 1304-1320. [CrossRef] [PubMed]

31. Paknejad, F.; Nasri, M.; Moghadam, H.R.T.; Zahedi, H.; Alahmadi, M.J. Effects of drought stress on chlorophyll fluorescence parameters, chlorophyll content and grain yield of wheat cultivars. J. Biol. Sci. 2007, 7, 841-847.

32. Bechtold, U.; Field, B. Molecular mechanisms controlling plant growth during abiotic stress. J. Exp. Bot. 2018, 69, 2753-2758. [CrossRef]

33. Bosabalidis, A.M.; Kofidis, G. Comparative effects of drought stress on leaf anatomy of two olive cultivars. Plant Sci. 2002, 163, 375-379. [CrossRef]

34. Zhang, C.; Yang, H.; Wu, W.; Li, W. Effect of drought stress on physiological changes and leaf surface morphology in the blackberry. Braz. J. Bot. 2017, 40, 625-634. [CrossRef]

35. Liu, F.; Stützel, H. Biomass partitioning, specific leaf area, and water use efficiency of vegetable amaranth (Amaranthus spp.) in response to drought stress. Sci. Hortic. 2004, 102, 15-27. [CrossRef]

36. Wullschleger, S.D.; Yin, T.M.; DiFazio, S.P.; Tschaplinski, T.J.; Gunter, L.E.; Davis, M.F.; Tuskan, G.A. Phenotypic variation in growth and biomass distribution for two advanced-generation pedigrees of hybrid poplar. Can. J. For. Res. 2005, 35, 1779-1789. [CrossRef]

37. Dong, S.; Jiang, Y.; Dong, Y.; Wang, L.; Wang, W.; Ma, Z.; Yan, C.; Ma, C.; Liu, L. A study on soybean responses to drought stress and rehydration. Saudi. J. Biol. Sci.. in press. [CrossRef]

38. Caine, R.S.; Xiaojia, Y.; Sloan, J.; Harrison, E.L.; Mohammed, U.; Fulton, T.; Biswal, A.K.; Dionora, J.; Chater, C.C.; Coe, R.A.; et al. Rice with reduced stomatal density conserves water and has improved drought tolerance under future climate conditions. New Phytol. 2018, 221, 371-384. [CrossRef] [PubMed]

39. Cheruiyot, E.K.; Mumera, L.M.; Ng'etich, W.K.; Hassanali, A.; Wachira, F. Polyphenols as potential indicators for drought tolerance in tea (Camellia sinensis L.). Biosci. Biotechnol Biochem. 2007, 71, 2190-2197. [CrossRef] [PubMed]

40. Sarker, U.; Oba, S. Drought stress enhances nutritional and bioactive compounds, phenolic acids and antioxidant capacity of Amaranthus leafy vegetable. BMC Plant Biol. 2018, 18, 258. [CrossRef] [PubMed]

41. Landi, S.; Nurcato, R.; De Lillo, A.; Lentini, M.; Grillo, S.; Esposito, S. Glucose-6-phosphate dehydrogenase plays a central role in the response of tomato (Solanum lycopersicum) plants to short and long-term drought. Plant Physiol. Biochem. 2016, 105, 79-89. [CrossRef]

42. Sánchez-Rodríguez, E.; Rubio-Wilhelmi, M.; Cervilla, L.M.; Blasco, B.; Rios, J.J.; Rosales, M.A.; Luis Romero, L.; Ruiz, J.M. Genotypic differences in some physiological parameters symptomatic for oxidative stress under moderate drought in tomato plants. Plant. Sci. 2010, 178, 30-40. [CrossRef] 
43. Živčák, M.; Brestič, M.; Olšovská, K.; Slámka, P. Performance index as a sensitive indicator of water stress in Triticum aestivum L. Plant Soil Environ. 2008, 54, 133-139. [CrossRef]

44. Hageage, G.J.; Harrington, B.J. Use of Calcofluor White in clinical mycology. Lab. Med. 1984, 15, $109-112$. [CrossRef]

45. Lee, S.; Seo, P.J.; Lee, H.-J.; Park, C.-M. A NAC transcription factor NTL4 promotes reactive oxygen species production during drought-induced leaf senescence in Arabidopsis. Plant. J. 2012, 70, 831-844. [CrossRef] [PubMed]

46. Benzie, I.F.F.; Strain, J.J. The ferric reducing ability of plasma (FRAP) as a measure of "antioxidant power": The FRAP assay. Anal. Biochem. 1996, 239, 70-76. [CrossRef] [PubMed]

47. Singleton, V.L.; Rossi, J.A. Colorimetry of total phenolics with phosphomolybdic-phosphotungstic acid reagents. Am. J. Enol. Vitic. 1965, 16, 144-158.

48. Smirnova, L.P.; Pervykh, L.N. Quantitative determination of the total content of flavonoids in the flowers of immortelle Helichrysum arenarium. Pharm. Chem. J. 1998, 32, 321-324. [CrossRef]

49. Foyer, C.H.; Shigeoka, S. Understanding oxidative stress and antioxidant functions to enhance photosynthesis. Plant Physiol. 2011, 155, 93-100. [CrossRef] [PubMed]

(C) 2019 by the authors. Licensee MDPI, Basel, Switzerland. This article is an open access article distributed under the terms and conditions of the Creative Commons Attribution (CC BY) license (http://creativecommons.org/licenses/by/4.0/). 